\title{
Nest-site fidelity and breeding dispersal by Common Tailorbirds in a tropical forest
}

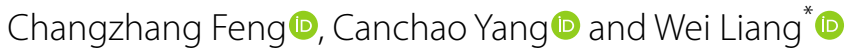

\begin{abstract}
Background: Information pertaining to nest-site fidelity and breeding dispersal over successive years can help to better our understanding of how birds respond to nest predation.

Methods: By using mist nets and tracking the color banded individuals, we investigated nest-site fidelity and breeding dispersal by Common Tailorbirds (Orthotomus sutorius) throughout a year and between successive years in 2017-2018.

Results: The present study showed that Common Tailorbirds could produce up to four clutches per breeding season. When multiple broods were produced within a year, breeding pairs remained together, and the nest rebuilding rate was up to $92.2 \%$, with only four cases (7.8\%) in which birds reused their old nests. The dispersal distance between the nests during multiple breeding was found to be $10.0 \pm 10.5 \mathrm{~m}$, and nest-site fidelity within the same year was $90.0 \%$. By the second year of breeding, $76.2 \%$ of individuals remained in the original breeding pairs, while for those that did switch partners, the females remained in the nest from the previous year and paired with new males. The dispersal distance between years was $26.5 \pm 41.9 \mathrm{~m}$, and nest-site fidelity between different years was $80.1 \%$. There was no significant difference between within-year and between-year dispersal distances. Moreover, there was no significant difference in the dispersal distance of rebuilt nests between birds that had experienced nest predation and those that had not.
\end{abstract}

Conclusions: Our findings suggest that Common Tailorbirds maintain a high degree of fidelity to mates and nestsites, and nest predation had no significant effect on territorial changes or breeding dispersal distance between each breeding attempt.

Keywords: Nest predation, Nest-site fidelity, Multiple breeding, Mate change, Tropical birds

\section{Background}

Nest predation is a major cause for avian breeding failure (Lack 1966; Skutch 1985; Martin 1995) and parent birds adopt a series of anti-nest-predation strategies to increase the survival rate of offspring (Martin 1995; Lima 2009). Selection of a safe and concealed nest-site is important for breeding success (Collias and Collias 1984; Martin 1995; Macdonald et al. 2016). Nest predation exerts pressure on breeding birds that determines nest-site selection and fidelity (Martin and Roper 1988; Parejo and Avilés 2011). Escaping from dangerous areas by moving farther

*Correspondence: liangwei@hainnu.edu.cn

Ministry of Education Key Laboratory for Ecology of Tropical Islands,

College of Life Sciences, Hainan Normal University, Haikou 571158, China away is a common coping strategy for certain birds to defend against nest predation (Collias and Collias 1984; Beckmann et al. 2015). Tropical birds have a much higher predation rate than temperate birds (Skutch 1985). High levels of nest predation may lead to increased numbers of birds producing multiple broods in a season to compensate for predator-caused breeding failure (Stutchbury and Morton 2001; Grzybowski and Pease 2005). Therefore, reducing the risk of nest predation in each reproductive attempt is particularly important for tropical birds (Skutch 1985). Birds either retain their nest-sites between each reproductive attempt or they move to establish a new nest-site depending on the potential benefits and costs of such action (Schmidt 2001). 
For some birds, maintaining a high degree of fidelity to nest-sites has several benefits including familiarity with foraging and shelter sites (Greenwood and Harvey 1982), mates (Rowley 1983), and neighbors (Yasukawa 1979; Picman 1987). Compared with changing nest-sites, breeding in familiar surroundings may increase predator avoidance and, thus, breeding success. Therefore, high nest-site fidelity is common for many monogamous birds (Greenwood and Harvey 1982). For example, 70\% of Magpie (Pica pica) parents will return to their original nest-site in the next year, regardless of their reproductive success in the previous year (Dhindsa and Boag 1992). Male and female birds differ in their fidelity to nest-sites, and males show greater fidelity to previous nesting areas than females (Greenwood 1980; Friedrich et al. 2015). This is possibly because males are unable to establish territories in occupied areas, or because females are more likely to find new areas with unmatched males (Greenwood and Harvey 1982).

Although there are many advantages to remaining at a nest-site, to reduce the risk of predation, birds may travel longer distances to establish the new nest-site in an area that does not have predators (Graves et al. 1986; BergerTal et al. 2010). Birds assess predation risk when choosing a nest-site based on previous breeding experience (Martin 1993). Therefore, birds that have reproduced successfully are more likely to breed at the same site, and those that have experienced nest predation are more likely to migrate to another breeding site (Powell and Frasch 2000; Beckmann et al. 2015). This predator-avoidance behavior may represent an adaptive strategy, but there are also studies that have reported different results. Beletsky and Orians (1991) found that nest-site changing frequency of female Red-winged Blackbirds (Agelaius phoeniceus) was independent of nest predation. Young et al. (2015) also found that parent Crimson Finches (Neochmia phaeton) did not move farther away after nest predation compared with those that bred successfully. The ability to change nest-sites is evidently an important adaptive strategy for birds, but it may vary between the sexes or among different species. The mechanism underlying nest-site selection may be multifaceted, including changing nest height and concealment (Kearns and Rodewald 2013; Beckmann et al. 2015) while moving away from the predatory area is the most common (Lima 2009).

The Common Tailorbird (Orthotomus sutorius) is a small passerine bird $(\sim 8 \mathrm{~g})$ widely distributed in the tropical areas of southwestern China, and is the main host of the Plaintive Cuckoo (Cacomantis merulinus) (Yang et al. 2016; Tunheim et al. 2019). In the present study, we tracked the reproductive behavior of the Common Tailorbird for 2 years (2017-2018). The predation avoidance ability of the Common Tailorbird through changing nest-sites was evaluated, and nest-site fidelity, breeding dispersal distances, and differences between males and females throughout a year and between successive years were measured.

\section{Methods \\ Study area and study species}

The study area was in Nonggang National Nature Reserve $\left(22^{\circ} 13^{\prime} \mathrm{N}, 106^{\circ} 42^{\prime} \mathrm{E}\right)$ of Guangxi, southwestern China. It has a typical tropical monsoon climate with an altitude of $150-650 \mathrm{~m}$. The average annual temperature is $20.8-$ $22.4{ }^{\circ} \mathrm{C}$ and the average annual rainfall is $1150-1550 \mathrm{~mm}$ (Zhou and Jiang 2008). The study was conducted during the breeding seasons of 2017-2018 (March-September). Nest locations were recorded by a GPS. The nests were monitored every other day to determine times for nesting, egg-laying, incubation, hatching, and successful fledging. At the same time, the predation date of eggs and chicks and the predators present in the area were recorded. A successful nest was defined as successful when it produced at least one fledgling, while nests found empty, containing eggshell fragments or dead nestlings were defined as depredated (Yang et al. 2011).

In the breeding season, the adult birds of Common Tailorbirds were captured by mist nets, and a colored metal ring with a unique number (National Band \& Tag Company, Newport, KY, USA) was attached to each captured bird. Sex was recorded and body measurements taken. The breeding behavior of the marked birds in the study area was then tracked.

\section{Measuring dispersal distance}

We introduced the size of the territory to compare with the dispersal distance. The territory size was estimated according to the method of Clark and Evans (1954). The territory was assumed to be circular and was centered on the nest. The radius of the territory was equal to half of the average distance to the nearest neighbor. The distance was determined using a GPS to record all nest locations on the map and by measuring the distance between the nests. These distances were used to analyze the dispersal distance and the size of the territory each time the nest was rebuilt. The within-year dispersal distance was the distance between the two nests during a breeding season. The between-year dispersal distance was the distance between an individual's final nest from 2017 and its new nest in 2018. When the dispersal distance was greater than the radius of the territory, it was considered to constitute a territorial change. However, when the distance was smaller than the radius of the territory, it was considered to represent maintained fidelity. 


\section{Data analyses}

A one-sample Kolmogorov-Smirnov test was used to test the normality of the data distribution to compare the differences among dispersal distances. When the data were normally distributed, the t-test was used to compare the means. When the data were not normally distributed, the Mann-Whitney U test was used instead. Differences in the probability of territory change were tested with Chi square test or Fisher's exact test. All tests were twotailed with a significance level of $p<0.05$. The data were expressed as mean \pm standard deviation (Mean $\pm S D$ ). Data analysis was performed in IBM SPSS 22.0 software (IBM Corp., Armonk, NY, USA). In order to avoid measuring the dispersal distance of the same individual repeatedly, we only measure the dispersal distance of individuals when they first re-nest after the predation event or a previous successful attempt.

\section{Results}

\section{Breeding period and clutch size}

Our study site approximately $24 \mathrm{~km}^{2}$. A total of 132 and 147 nests were found in 2017 and 2018, respectively, and the breeding density was 5.8 nests $/ \mathrm{km}^{2}$. The Common Tailorbird is a social monogamous resident and the breeding season of this bird lasts about 7 months, from March to the end of September. This bird mainly builds its nest in broad-leaf forests or shrubs at the edges of mountains. Both females and males build nests. The nests are built by stitching together 1-3 leaves and then filling with nest materials. The clutch size is $3-5$ eggs (for the first clutch, $n=40$ ). The nesting period is $3-5$ days, the egg-laying period is $2-6$ days, the incubation period is 12 days, and the nestling feeding period is 12 days, with a minimum breeding period being about 35 days. Only females incubate, but both parents care for the young until nestling fledged.

A total of 89 breeding pairs were marked in 2017-2018, and the tracked record showed that the Common Tailorbird can produce up to four clutches within a single breeding season. The probability of re-nesting after nest predation was $61.5 \%(n=39)$, and the probability of renesting after successful attempt was $32.0 \%(n=50)$, thus the probability of re-nesting after predation and successful breeding was significant $\left(\chi^{2}=7.726, \mathrm{df}=1, p=0.005\right)$. The radius of the territory was determined by the minimum neighbor distance as $31.4 \pm 15.3 \mathrm{~m}(n=96)$ (Fig. 1$)$, with about $0.003 \mathrm{~km}^{2}$ in territorial area.

\section{Dispersal distance and territory change within a breeding season}

In 2 years, re-nesting attempts were observed in 40 pairs of breeding birds, and there was no significant difference

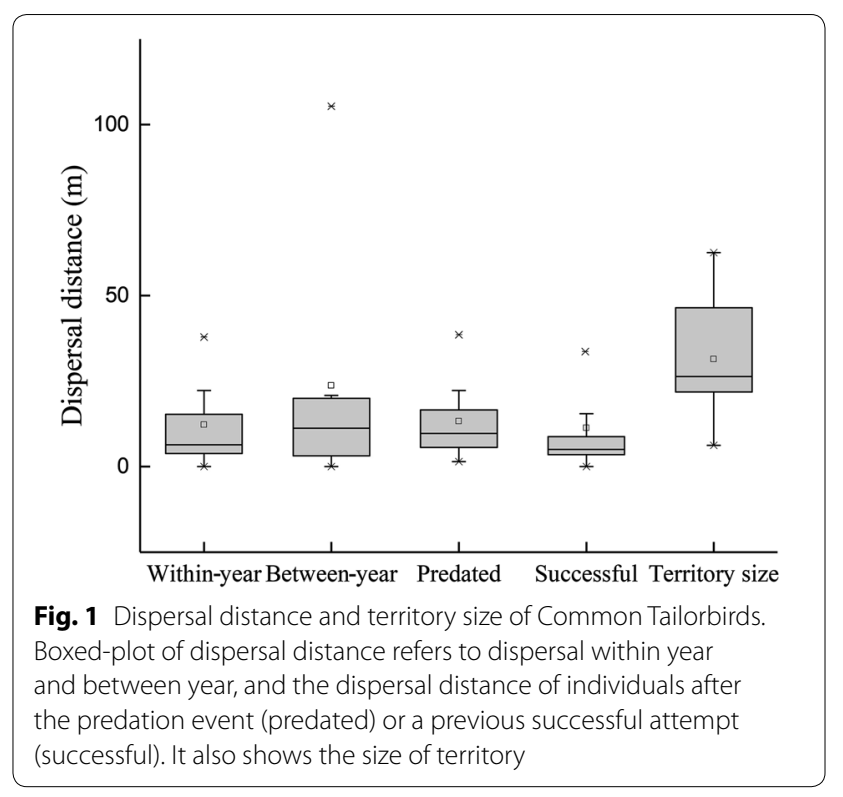

in the dispersal distance between 2017 and 2018 when the nest was re-built $(Z=-1.091, p=0.279)$. When multiple breeding occurred, the original mating relationship was maintained, and thus, the nest-site fidelity of males and females was the same within a year. Most Common Tailorbirds built a new nest after the first breeding attempt $(n=36)$. The dispersal distance of new nests was $0-43.2 \mathrm{~m}$, with an average of $10.0 \pm 10.5 \mathrm{~m}$ (Fig. 1). Only four breeding pairs reused their old nests. In multiple breeding, the dispersal distance was shorter than the radius of the territory, indicating that within-year nestsite fidelity was $90.0 \%$. Only four nests were constructed in new territories, and their dispersal distances (31.7$43.2 \mathrm{~m}$ ) were less than the size of territory.

\section{Dispersal distance and territory change between year}

In 2018, we rediscovered 21 breeding nests built by marked birds from 2017. Compared with the nest-site location of the previous year, the dispersal distance of these 21 nests was $0-105.4 \mathrm{~m}$, with an average distance of $23.7 \pm 33.1 \mathrm{~m}$ (Fig. 1). The dispersal distance was less than the territory radius in most of re-nesting attempts, meaning that the nest-site fidelity was $81 \%$. Both males and females showed relatively high nest-site fidelity in the second year (Table 1). The mating relationship in these 21 nests of marked birds was also changed, with $76.2 \%$ of individuals being remained in the original pairs. Of the 17 nests that remained in the original nest-sites, 13 also retained their initial pairs. In the remaining four nests, the marked females were paired with new males. Four nests were dispersed to new territories, and three 
Table 1 The probability of territorial changes in Common Tailorbirds

\begin{tabular}{|c|c|c|c|c|c|c|}
\hline & New (\%) & Same (\%) & $n$ & $x^{2}$ & df & $p$ \\
\hline Within-year & $4(10.0)$ & $36(90.0)$ & 40 & 0.355 & 1 & 0.552 \\
\hline Between-year & $4(19.0)$ & $17(81)$ & 21 & & & \\
\hline Predated & $2(12.5)$ & 14 (87.5) & 16 & 0.012 & 1 & 0.194 \\
\hline Successful & $2(8.3)$ & $22(91.7)$ & 24 & & & \\
\hline Female & $4(19.0)$ & $17(81)$ & 21 & 1.867 & 1 & 0.172 \\
\hline Male & $8(38.1)$ & $13(61.9)$ & 21 & & & \\
\hline
\end{tabular}

Probability of territorial changes showed how breeding individuals changed territories within year and between year, between the male and female, and between individuals after the predation event (predated) and a previous successful attempt (successful)

nests maintained their original mating relationship and a marked female paired with a new male.

For within-year and between-year comparisons, there was no significant difference in dispersal distance (within-year: $10.0 \mathrm{~m}$; between-year: $23.7 \mathrm{~m} ; Z=-1.146$, $p=0.252$ ). There was also no statistical difference between within- and between breeding season dispersal in territorial changes $\left(x^{2}=0.335, \mathrm{df}=1, p=0.552\right)$ (Table 1).

\section{Effects of nest predation on nest-site change}

A total of $40 \mathrm{~s}$ nesting attempts were observed, and they were defined as either successful or predated. Nest-site dispersal distance for breeding failure caused by predation was $1.5-43.2 \mathrm{~m}$, and the average distance was $12.3 \pm 12.1 \mathrm{~m}$ (Fig. 1). The nest-site dispersal distance for a successful breeding was $0-35.4 \mathrm{~m}$, and the average distance was $8.5 \pm 9.2 \mathrm{~m}$ (Fig. 1). There was no significant difference in the dispersal distance between predation and successful breeding $(Z=-1.423, p=0.157)$.

In a single breeding season, when the last breeding was successful, three out of 27 cases moved to a new territory for the next reproductive attempt, while three out of 24 cases moved following predation, and there was no significant difference $\left(\mathrm{X}^{2}=0.012, \mathrm{df}=1, p=0.194\right)$ (Table 1 ).

\section{Discussion}

Common tailorbirds in our study area could lay eggs up to four clutches within a breeding season. Mates tended to remain together throughout a breeding season and in the second year. The scale of study area was much larger than average home ranges and dispersal distances, indicating that breeding pairs had the opportunity to switch to the new territories. There was no significant difference between the within-year and between-year dispersal distances indicating high nest-site fidelity. The probability of territorial changes between sexes was not significant, showing that the occupation and maintenance of nest-sites may be dominated by both females and males. The dispersal distance following nest predation was not significantly different to the dispersal distance after successfully breeding, and most of the birds reproduced in their original territory, suggesting that nest predation does not exert a strong pressure on birds to travel further to avoid such risk.

\section{Nest-site fidelity and individual difference between males and females}

Birds maintain a high level of fidelity and possessiveness for their territory during the breeding season (Greenwood and Harvey 1982), and some even reuse their old nests for multiple breeding attempts within a breeding season (Barclay 1988). In our study, Common Tailorbirds rebuilt their nests for each breeding attempt but remained in the same territories throughout the study period. The benefits of nest-site fidelity include familiarity with feeding and shelter sites (Greenwood and Harvey 1982), partners (Rowley 1983; Schieck and Hannon 1989), and neighboring nests (Yasukawa 1979; Picman 1987). Tropical birds have higher adult survival rate, smaller clutch size, and higher nest predation pressure than temperate bird species (Stutchbury and Morton 2001; Jiang et al. 2017). During the breeding season, Common Tailorbirds maintain close mating relationships and a high degree of territorial fidelity, with most of the birds that remained in the same territory also retaining their mates from the previous year. Given that territorial saturation may limit animal movement, particularly in tropical species (Freed 1987), the possibility of the effect of population density on dispersal distances and the existence of movements outside the study site needed further investigation.

In many monogamous birds, males have been reported to be more loyal to their former breeding areas than females (Greenwood and Harvey 1982). This is because males need to protect their resources to attract females, and females choose their mates by observing the quality of their defensive resources (Greenwood 1980). The results of our study showed that both males and females had high fidelity to their original territory in the following 
year, which indicated that male and female Common Tailorbirds are both dominant territorially.

\section{Effects of nest predation on nest-site change}

Anti-nest predation is a key adaptation in the evolution of bird life history (Martin and Roper 1988; Martin 1995). Birds make decisions based on their previous experience. After experiencing nest predation, they escape by moving away from the dangerous area, which is a common strategy for birds to avoid such risks (Berger-Tal et al. 2010; Beckmann et al. 2015). Contrary to the results of Berger-Tal et al. (2010) and Beckmann et al. (2015), our study indicate that nest predation does not exert a significant influence on the decision-making process of Common Tailorbirds for changing their nest sites, evidenced by breeding dispersal distance. Although the probability of re-nesting after predation was higher than that of successful breeding, nest predation did not cause Common Tailorbirds to move to a different nest site, and the vast majority of them remained in their initial territory. These results are similar to those found by Young et al. (2015) and Beletsky and Orians (1991), in that the nest-site changing frequency and moving distance were independent of nest predation in the previous year. One reason for the birds remaining in a nesting area with predators is that dispersal to other places does not reduce the risk of nest predation. It may even increase unknown dangers because the new environment is unfamiliar, and thus, moving to a new nest site is less beneficial to reproductive success than remaining in an area with predators (Fisher and Wiebe 2006). Choosing to remain in their territory can also save the time and energy spent finding suitable nest sites (Powell and Frasch 2000; Shutler and Clark 2003).

Another possible reason for these birds remaining in their initial territory is that they may be able to reduce nest predation by modifying the characteristics of the nest-site (Young et al. 2015). The dense forests in the study area provide many potential nesting sites with different characteristics. For example, increased nesting height and concealment would be beneficial for avoiding nest predation. We did not investigate these characteristics in the present study, and the mechanisms underlying these choices may be multifaceted. Meanwhile, we also found that, in parents that changed their nest sites, the dispersal distance was between one and two territory radii, indicating that they only moved to nearby familiar territories. No other birds had reproduced in these areas before, which suggests that undersaturation may be another condition for birds to disperse to other territories. If the breeding birds did not adapt to their previous experience of predation by changing the dispersal distance in subsequent breeding attempts, then it is possible that the birds instead reduced the risk of nest predation by changing the height or concealment of nest-sites (Marzluff 1988).

Future studies should investigate the relationship between the characteristics of nest-site selection and breeding success more comprehensively. In this study, we were unable to compare the breeding success between those birds that had dispersed and those that remained in the same territory in the second year. Out of breeding season, Common Tailorbirds have sufficient time to select an ideal nest-site; however, we observed that, no matter whether their nests were preyed upon or succeeded during the previous year or the previous breeding attempt in the same year, they remained active in, and retained possession of, their original territory. Unfortunately, the study period was only until the end of September, therefore, we did not collect territorial data for non-breeding season, and thus, the behavior of these birds remains unclear. Dominance during winter plays an important role in bird population dynamics and pre-reproduction period (Holmes et al. 1989). Future studies should focus on the role of territory during the non-breeding period.

\section{Conclusions}

Our study explicated a high nest-site fidelity and low breeding dispersal of Common Tailorbirds within a single breeding season and spanning over 2 years. We showed that Common Tailorbirds have high levels of mating and nest-site fidelity, and that both the males and females dominate the nest-site. Their dispersal patterns are the same within the same year and between different years, suggesting that most of them remain in their original territory to rebuild their nests. The probability of re-nesting after predation was higher than that of successful breeding, however, nest predation did not appear to cause higher dispersal distances in Common Tailorbirds for rebuilding nests.

\section{Acknowledgements \\ We are grateful to two anonymous referees for their constructive comments. We would like to thank Nonggang National Nature Reserve for their help and cooperation, and Bo Zhou and Jianchou Nong for their assistance with field work.}

\section{Authors' contributions}

WL designed the study; CF carried out field experiments; CY performed laboratory and statistical analyses. CF wrote the draft manuscript, and WL helped improve the manuscript. All authors read and approved the final manuscript.

\section{Funding}

This work was funded by the National Natural Science Foundation of China (Nos. 31472013 and 31772453 to WL).

\section{Availability of data and materials}

The datasets used and/or analyzed during the current study are available from the corresponding author on reasonable request. 


\section{Ethical approval and consent to participate}

The experiments reported here comply with the current laws of China. Fieldwork was carried out under the permission from Nonggang National Nature Reserve, China. Experimental procedures were in agreement with the Animal Research Ethics Committee of Hainan Provincial Education Centre for Ecology and Environment, Hainan Normal University (permit no. HNECEE-2012-002).

\section{Consent for publication}

Not applicable.

\section{Competing interests}

The authors declare that they have no competing interests.

Received: 1 May 2019 Accepted: 29 October 2019

Published online: 19 November 2019

\section{References}

Barclay RMR. Variation in the costs, benefits, and frequency of nest reuse by barn swallows (Hirundo rustica). Auk. 1988;105:53-60

Beckmann C, Biro PA, Martin K. Hierarchical analysis of avian re-nesting behavior: mean, across-individual, and intra-individual responses. Behav Ecol Sociobiol. 2015:69:1631-8.

Beletsky LD, Orians GH. Effects of breeding experience and familiarity on site fidelity in female red-winged blackbirds. Ecology. 1991;72:787-96.

Berger-Tal R, Berger-Tal O, Munro K. Nest desertion by grey fantails during nest building in response to perceived predation risk. J Field Ornithol. 2010:81:151-4.

Clark PT, Evans FC. Distance to nearest neighbor as a measure of spatial relationships in populations. Ecology. 1954;35:445-53.

Collias NE, Collias EC. Nest building and bird behavior. Princeton: Princeton University Press; 1984

Dhindsa MS, Boag DA. Patterns of nest site, territory, and mate switching in black-billed magpies (Pica pica). Can J Zool. 1992;70:633-40.

Fisher RJ, Wiebe KL. Breeding dispersal of Northern Flickers Colaptes auratus in relation to natural nest predation and experimentally increased perception of predation risk. Ibis. 2006;148:772-81.

Freed LA. The long-term pair bond of tropical house wrens: advantage or constraint? Am Nat. 1987:130:507-25.

Friedrich MJ, Hunt KL, Catlin DH, Fraser JD. The importance of site to mate choice: mate and site fidelity in piping plovers. Auk. 2015;132:265-76.

Graves J, Whiten A, Henzi P. Reproductive success and the location of the nest site in the territory of the Herring Gull Larus argentatus. Bird Study. 1986;33:46-8.

Greenwood PJ, Harvey PH. The natal and breeding dispersal of birds. Annu Rev Ecol Syst. 1982;13:1-21.

Greenwood PJ. Mating systems, philopatry and dispersal in birds and mammals. Anim Behav. 1980;28:1140-62.

Grzybowski JA, Pease CM. Renesting determines seasonal fecundity in songbirds: what do we know? What should we assume? Auk 2005; 122:280-91.

Holmes RT, Sherry TW, Reitsma L. Population structure, territoriality and overwinter survival of two migrant warbler species in Jamaica. Condor. 1989;91:545-61.
Jiang A, Jiang D, Goodale E, Wen Y. Nest predation on birds that nest in rock cavities in a tropical limestone forest of southern China. Glob Ecol Conserv. 2017:10:154-8

Kearns $L$, Rodewald AD. Within-season use of public and private information on predation risk in nest-site selection. J Ornithol. 2013;154:163-72.

Lack D. Population studies of birds. Oxford: Clarendon Press; 1966.

Lima SL. Predators and the breeding bird: behavioral and reproductive flexibility under the risk of predation. Biol Rev. 2009;84:485-513.

Macdonald EC, Camfield AF, Martin M, Wilson S, Martin K. Nest-site selection and consequences for nest survival among three sympatric songbirds in an alpine environment. J Ornithol. 2016;157:1-13.

Martin TE. Nest predation and nest sites. Bioscience. 1993;43:523-32.

Martin TE. Avian life history evolution in relation to nest sites, nest predation, and food. Ecol Monogr. 1995:65:101-27.

Martin TE, Roper JJ. Nest predation and site selection of a western population of the hermit thrush. Condor. 1988:90:51-7.

Marzluff JM. Do pinyon jays alter nest placement based on prior experience? Anim Behav. 1988:36:1-10.

Parejo D, Avilés JM. Predation risk determines breeding territory choice in a Mediterranean cavity-nesting bird community. Oecologia. 2011;165:185-91.

Picman J. Territory establishment, size, and tenacity by male red-winged blackbirds. Auk. 1987;104:405-12.

Powell LA, Frasch LL. Can nest predation and predator type explain variation in dispersal of adult birds during the breeding season? Behav Ecol. 2000;11:437-43.

Rowley I. Re-mating in birds. In: Bateson P, editor. Mate choice. Cambridge: Cambridge University Press; 1983. p. 331-60.

Schieck JO, Hannon SJ. Breeding site fidelity in willow ptarmigan: the influence of previous reproductive success and familiarity with partner and territory. Oecologia. 1989;81:465-72.

Schmidt KA. Site fidelity in habitats with contrasting levels of nest predation and brood parasitism. Evol Ecol Res. 2001;3:553-65.

Shutler D, Clark RG. Causes and consequences of tree swallow (Tachycineta bicolor) dispersal in Saskatchewan. Auk. 2003;120:619-31.

Skutch AF. Clutch size, nesting success, and predation on nests of Neotropical birds, reviewed. Ornithol Monogr. 1985;36:575-94.

Stutchbury BJ, Morton ES. Behavioral ecology of tropical birds. London: Academic Press; 2001

Tunheim $\mathrm{OH}$, Stokke BG, Wang L, Yang C, Jiang A, Liang W, et al. Development and behavior of plaintive cuckoo (Cacomantis merulinus) nestlings and their common tailorbird (Orthotomus sutorius) hosts. Avian Res. 2019:10:5.

Yang C, Cai Y, Liang W, Antonov A. Breeding biology of the golden parrotbill (Paradoxornis verreauxi) (Aves: Timaliidae) in southwestern China. J Nat Hist. 2011:45:1817-22

Yang C, Huang Q, Wang L, Jiang A, Stokke BG, Fossøy F, et al. Plaintive cuckoos do not select tailorbird hosts that match the phenotypes of their own eggs. Behav Ecol. 2016;27:835-41.

Yasukawa K. Territory establishment in red-winged blackbirds: importance of aggressive behavior and experience. Condor. 1979;81:258-64.

Young CM, Cain KE, Svedin N, Backwell PR, Pryke R. Nesting success in crimson finches: chance or choice? Ethology. 2015;123:41-50.

Zhou F, Jiang A. A new species of babbler (Timaliidae: Stachyris) from the SinoVietnamese border region of China. Auk. 2008;125:420-4. 